\title{
FE Analysis of Contact Pressure Prediction on O-Rings Used in Solid Rocket Booster Segment Joints
}

\author{
V. Sivakumar \\ Department of Aerospace Engineering, \\ Amrita Vishwa Vidyapeetham University, \\ Amrita Nagar, Coimbatore, India.
}

\author{
R. Palaninathan \\ Department of Applied Mechanics, \\ Indian Institute of Technology, Madras, \\ Chennai, India.
}

\begin{abstract}
This paper presents an analysis to predict the gap and contact pressure existence in segment joint used in Solid Rocket Boosters using 3-D finite element (FE) as a general nonlinear problem. The relevant components, the tang, the clevis and pin are modeled individually and assembled. The FE modeling includes O-Rings as integral part of joint, which brings out the deformation of seals and contact pressure (CP) between O-Rings and the casings as a function of external loads. The general purpose FE package ABAQUS for analysis and HYPERMESH for pre- and post- processing are employed. The CP between the O-Rings and the slot walls in the joint depends very much on the material properties. The initial $\mathrm{CP}$ induced during assembly of segments is higher for lower ambient temperatures and lower for higher temperatures.
\end{abstract}

Keywords: Contact Pressure, Segment joints, nonlinear, O-Rings

\section{INTRODUCTION}

Solid rocket boosters (SRB), Figure 1 are being used extensively, since the advent of modern space technology, as it offers several advantages. SRBs of varying sizes (diameter: $1.0-3.7 \mathrm{~m}$, length: $20.0-40.0 \mathrm{~m}$ ) are in use in different mission of space launches: space shuttles (USA), GSLV, PSLV (India). Due to the large size and heavy weight, they are made in segments. There are two types of joints in SRBs, factory made and field joints. The segments are made from thin sheet material by conventional rolling and welding (factory made) and cast with solid propellant. The cast

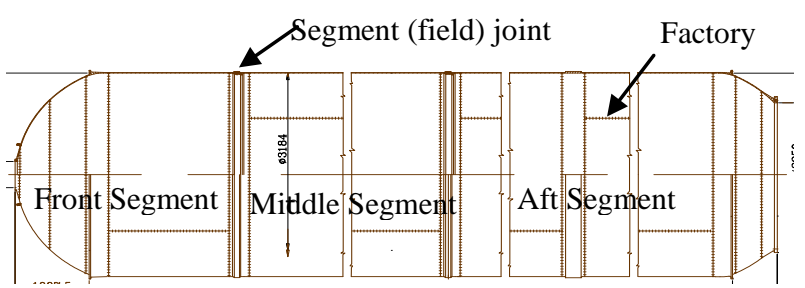

Figure 1. Sketch of solid rocket booster casing

segments are assembled one over the other by using special type of joints (field joints, Fig.2) [12], as the welding of the cast segment is not permitted. The sealing efficiency of the field joints are concern to the designer. The tang-clevis joint consists of: (i) clevis, the female part in one segment; (ii) tang, the male part in the adjacent segment, (iii) pins and (iv) O-Rings (primary and secondary of polymeric material). The O-Ring provides pressure seal to prevent the leakage of hot combustion gasses during operation. The effectiveness of the O-Rings depends on the relative displacements of the parts. Several structural characteristics of the segment joint have been identified as potential contributors to the failures [2]. One characteristic is the behavior of the joint under internal pressure, the primary load. The motor case expands radially outward due to the pressure, because the joint has higher hoop stiffness than the case wall on either side of the joint. Its differential radial expansion is primary cause of relative displacement between the inner clevis flange and the sealing surface on the tang. The relative displacement can cause the
O-Rings to become unseated and, therefore, loose their sealing efficiency.

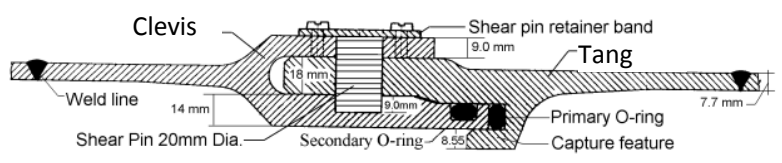

Figure 2. Details of Segment Joint

\section{LITERATURE REVIEW}

Solid Rocket Boosters (SRB) are in the use for several years as launch vehicles. However the details of design and analyses of the same are not available in open literature as they are of classified nature. Only a few studies have been reported in the open literature. Study on the joint is mainly divided into two broad areas; structural analysis and thermo mechanical analysis of the O-Rings. Studies on structural part were discussed by the authors in their previous works, Sivakumar V [16]. With respect to thermo mechanical part, Mark Salita [11] developed a computer code "ORINGDEF" to study the response of the O-Rings kept within slots of specially made experimental setup, subjected to different pressure levels. The study did not consider the O-Ring behavior in a segment joint of an actual motor case. They did not estimate the contact pressure between the O-Ring and the slot wall. Kenneth Parsons Jr. [7] carried out experimental investigation on leak characteristic of segment and nozzle-segment joints with $\mathrm{O}$ Rings made up of viton. Nitrogen gas pressure in the range of $0.21-6.89 \mathrm{MPa}$ was applied in the test for two different temperatures; ambient and $120^{\circ} \mathrm{F}(322 \mathrm{~K})$. The objective of the study was to quantify the performance of the O-Rings for various test conditions; grease blocking and absorption and exudation of nitrogen gases. Perry et al. $[13,14]$ carried out thermal analysis and experiments on segment joints. The analyses were carried out for three conditions: (1) design case, (2) single leak path and (3) double leak path. In the design case (assumed normal operation of the field joint insulation), the temperature predicted at the O-Ring regions were low (close to ambient level), whereas under the other two cases, the capture feature O-Ring was shown to experience 
temperature of the order of $3033 \mathrm{~K}$. The temperatures felt in primary and secondary O-Rings for the single leak condition was shown to be in the range of 416 to $517 \mathrm{~K}$. Similar investigations were carried out on the segment joints with $\mathrm{O}$ Rings included in modeling by Wienholts and Nguyen [18]. They used different software, namely 'PHOENICS" and the temperature field varying with time (transient condition) were assumed. The surface temperature at the capture feature O-

Ring was found to be $4100^{\circ} \mathrm{F}(2533 \mathrm{~K})$ at $\mathrm{t}=0.6 \mathrm{sec}$, which was found to reduce to $600^{\circ} \mathrm{F}(589 \mathrm{~K})$ at $2.5 \mathrm{sec}$. Lach $[9,10]$ conducted tests on three elastomeric O-Ring materials; Viton, Nitrile and Silicone for their resiliency behavior under the effects of temperature and gap opening rates. He found that the resiliency of the materials is extremely sensitive to temperature and gap opening rate. Ruddell and Buttars [15] carried out an experimental investigation on the JPS of the redesigned solid rocket motor (RSRM). The RSRM segment joint was having a heater fixed close to the O-Rings, radially on the outer surface of the casing in the JPS. The experiments were conducted by blowing the cold air on the outer surface to create a condition of cold weather. The capacity of the heater was obtained such that the stabilized temperature was $75^{\circ} \mathrm{F}$ $(297 \mathrm{~K})$ and above in order to maintain the sufficient resiliency in the O-Ring material. Stein [17] stressed the importance of seal material selection and reliable design and performance of the O-Ring material.

The present work is an attempt in this direction. Finite element (FE) method of analyses has been performed to predict deformations and contact pressure developed between O-Rings and adjacent slot walls of tang-clevis type segment joint. The analyses are carried out using 3-D solid element, treating it as a fully nonlinear problem $[4,5]$. The nonlinearity comes in three ways: (i) material nonlinear, (ii) geometric nonlinear and (iii) contact nonlinear. The $\mathrm{CP}$ at the interfaces between elastomeric O-Rings and the casing is responsible for arresting the gas leakage. This paper presents a study on the joint including the O-Rings in the FE model as an integral part to compute the values of the contact pressure exerted by the O-Rings on the slot walls as the casing is subjected to loads; combustion pressure, leaked gas pressure and temperatures.

\section{FE MODELING}

\subsection{Modeling of Segment Joint}

Figure 2 shows the axial section of a typical segment joint. A total of 180 pins spaced equally around the joint circumference to attach the segments. Due to cyclic symmetry, only a small segment, bearing an angle equal to $2 \pi / n$ in the circumferential direction is considered, where ' $n$ ' is the number of pins. The CAD modeling is carried out using PRO-E and FE idealization is obtained using Hypermesh. ABAQUS [1] general purpose FE software has been employed in the solution. Maraging steel (properties: yield stress, $\sigma_{\mathbf{y}}=1482 \mathrm{MPa}$., ultimate stress, $\sigma_{\mathbf{u}}=1793 \mathrm{MPa}$. and ultimate strain, $\boldsymbol{\varepsilon}_{\mathbf{u}}=1.16 \%$ ) is used for casing and the pin. The combustion pressure of $6.47 \mathrm{MPa}$ is applied on the inner surface. The tang, the clevis, the pin and the O-Rings are modeled separately and assembled exactly the way in which the segment joints are realized in practice (Figure 3). In order to take the modeling to the membrane region, extended length of $250 \mathrm{~mm}$ are added either side of the weld line (Figure 2). The contact surfaces are defined at appropriate locations. The FE idealization consists of 64000 nodes and 51000 eight node brick elements. The symmetry boundary conditions are applied at the edges.
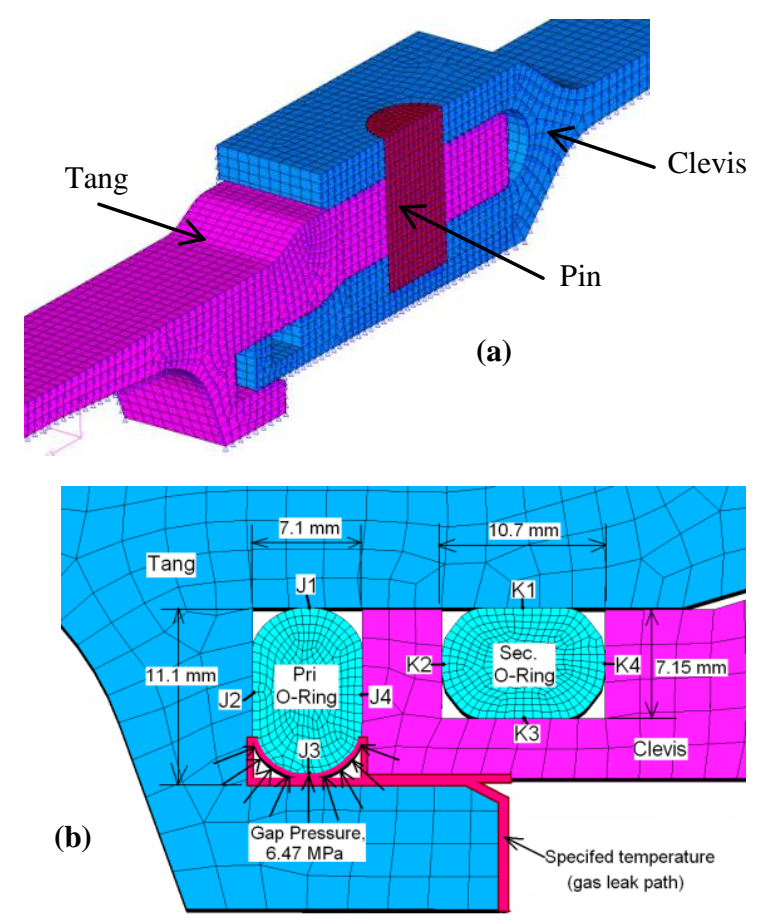

Figure 3. (a) FE idealization of segment joint, (b) Unloaded position of O-Rings, identification locations of $\mathrm{CP}$

\subsection{Modeling of O-Rings (Elastomers)}

The O-Rings are of polymeric materials. The considered segment joint with capture feature having two O-Rings, primary and secondary, Figure $3 \mathrm{~b}$. The main function of these rings is to arrest the gas leakages in case the combustion gases pass through the line of separation in the insulation, Figure 4. If this happens, the primary O-Ring is subjected to gas pressure and temperature directly. The sealing efficiency depends on the contact pressure (CP) exerted by the O-Rings on the casing walls / slots. The CP is induced / increased / decreased under the following conditions: (1) while inserting the O-Rings in to the joint during assembly, (2) structural deformation in the joint due to internal combustion pressure

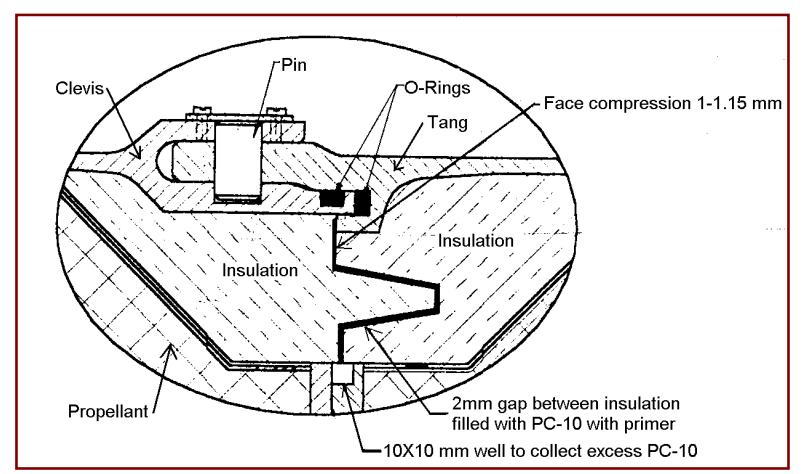

Figure 4. Details of joint with insulation and propellant assembly

(design load), (3) while leaking gas acts on the primary ORing and (4) due to friction between the O-Rings and the casing slots. The initial stage $\mathrm{CP}$ under first condition is due to dimensional difference between the O-Ring and the 
grooves / slots provided in a segment joint. The initial diameter of the O-Ring is assumed to be $9.5 \mathrm{~mm}$, against the groove dimensions of: 7.1 x $11.1 \mathrm{~mm}$ (primary O-Ring groove) and $7.15 \times 10.7 \mathrm{~mm}$ (secondary O-Ring groove), Figure $3 \mathrm{~b}$. In the FE modeling, the O-Ring insertion is carried out in two stages. Firstly, it is diametrically compressed to a value, slightly less than $7.15 \mathrm{~mm}$ from $9.5 \mathrm{~mm}$, while constraining the expansion in the perpendicular direction limited to the larger dimension of the slot $(11.1 \mathrm{~mm}$ for primary O-Ring and $10.7 \mathrm{~mm}$ for secondary O-Ring) by defining two sets of contact surfaces in the FE procedure. This stage is termed as "load step 0-1" (stage 1), Figure 5. The deformed shape of the primary $\mathrm{O}$-Ring at this stage is referred to as $\mathrm{C} 1$ (Figure $5 \mathrm{~b}$ ). Secondly, the compressed rings are allowed to expand thus establishing the initial $\mathrm{CP}$ on the slot walls. This stage is termed as "load step 1-2" (stage 2), Figure $5 \mathrm{c}$ and referred to as $\mathrm{C} 2$. The deformed configurations of the two O-Rings at the end of this stage are shown in Figure $3 \mathrm{~b}$. After squeezing and keeping the O-Rings in the slots in deformed configuration as mentioned above (first two stages), the analysis of the full joint is carried out under three more stages. In the third stage, casing is subjected to internal pressure (design load, 6.47 MPa). There are deformations and gap formations in the joint. This stage is termed as 'load step 2-3" (stage 3). These deformations cause further changes in the CP values. In the fourth stage, the leaked gas is allowed to act at bottom of primary O-Ring (Figure $3 b$ ). This is termed as "load step 3-4" (stage 4). The end of this step is referred to as C4. In the final stage, "load step 4-5" (stage 5), the thermal load from the leaking gas is applied as specified surface temperature at the bottom of primary O-Ring (Figure $3 \mathrm{~b}$ ). This stage is analyzed in two levels, firstly as a thermal problem to determine the temperature field and secondly as a structural problem to determine the deformations and the consequent changes in the $\mathrm{CP}$ values. Figure $3 \mathrm{~b}$ indicates the marked locations $\mathrm{J} 1-\mathrm{J} 4$ in primary O-Ring and $\mathrm{K} 1-\mathrm{K} 4$ in the secondary O-Ring at which the variations of $\mathrm{CP}$ values during

Table 1. VITON Material Properties (www.sealeastern.com, Wienholts [18],Anon [3].

\begin{tabular}{|l|l|}
\hline \multicolumn{1}{|c|}{ Properties } & \multicolumn{1}{|c|}{ Values } \\
\hline Young's modulus, E & $\begin{array}{l}27.6 \mathrm{MPa} \text { at T }=- \\
25^{\circ} \mathrm{C}<5.0 \mathrm{MPa} \text { at T } \\
=25^{\circ} \mathrm{C}\end{array}$ \\
\hline Poisson's ratio, $v$ & 0.497 \\
\hline $\begin{array}{l}\text { Linear thermal expansion } \\
\text { coefficient, } \alpha\end{array}$ & $162.0 \mathrm{E}-06 \mathrm{~mm} / \mathrm{mm} \mathrm{K}^{\circ}$ \\
\hline Density, $\rho$ & $1090 \mathrm{E}-09 \mathrm{~kg} / \mathrm{mm}^{3}$ \\
\hline Thermal conductivity, $\mathrm{k}$ & $0.000343 \mathrm{~W} / \mathrm{mm} \mathrm{K}$ \\
\hline Specific heat, $\mathrm{C}$ & $1507 \mathrm{~J} / \mathrm{kg} \mathrm{K}$ \\
\hline
\end{tabular}

the load steps 2-5 are presented. In the above 5 stages of analyses, the properties of elastomeric material (VITAN, product name of elastomeric material used for O-Rings) presented in Table 1 are used. As seen from Figure 6, Young's modulus is dependent on temperature; for values

wWw.ijsea.com $<25^{\circ} \mathrm{C}$, it increases fast with decrease in temperature and remains constant for temperatures $>25^{\circ} \mathrm{C}$. Here the analyses are carried out for two ambient temperature levels, $-25^{\circ} \mathrm{C}$ and $25^{\circ} \mathrm{C}$. The Young's modulus for the former is $25.6 \mathrm{MPa}$ and for the later, it is $<5 \mathrm{MPa}$. The low temperature condition is referred to as Type 1 and the elevated temperature condition is referred to as Type2 in Figure 5. The Poisson's ratio of elastomeric material is approaching the value of 0.5 (nearly incompressible behavior). This condition leads to numerical instability in FE modeling. This situation becomes more acute for Young's modulus values $<7 \mathrm{MPa}$. This is because of collapse of elements, when deformation is taking place within a confined space. Numerical studies in this respect showed that the conventional linear elastic material modeling is enough for the above Type1 material, whereas for Type2 material one has to use hyperelastic material model. A characteristic stress-strain behavior of VITON at temperature $>25^{\circ} \mathrm{C}$ is shown in Figure 7.

In this study Mooney-Rivlin strain energy potential is used for the hyper-elastic material modeling of O-Rings with material model Type2.

The form of Mooney-Rivlin strain energy potential is (ABAQUS, [1]).

$$
\mathrm{U}=\mathrm{C}_{10}\left(\overline{\mathrm{I}}_{1}-3\right)+\mathrm{C}_{01}\left(\overline{\mathrm{I}}_{2}-3\right)+\frac{1}{\mathrm{D}_{1}}\left(\mathrm{~J}^{\mathrm{el}}-1\right)^{2}
$$

where,

$\mathrm{U}$ is the strain energy per unit of reference volume

$\mathrm{C}_{10}, \mathrm{C}_{01}$ and $\mathrm{D}_{1}$ are material parameters and

$\overline{\mathrm{I}}_{1}$ and $\overline{\mathrm{I}}_{2}$ are the first and second deviatoric strain invariants

If $D_{1}$ is equal to zero, the material is fully

incompressible.

In the above Equation, the material parameters $\mathrm{C}_{10}, \mathrm{C}_{01}$ can be calculated in the ABAQUS (ABAQUS, 2004) by using the material (VITON) stress-strain curve (www.polymerFEM.com). The appropriate incompressibity $\left(D_{1} \neq 0\right)$ is also considered in this analysis by assuming the Poisson's ratio 0.497 . With reference to the literature on the frictional coefficients, $\mu$ between the elastomeric material and the metals with lubricants (Anon, 2001), $\mu$ varies from 0.1 to 0.4 . Initially 0.4 (static friction) and later on reduces to 0.1 (dynamic friction). 


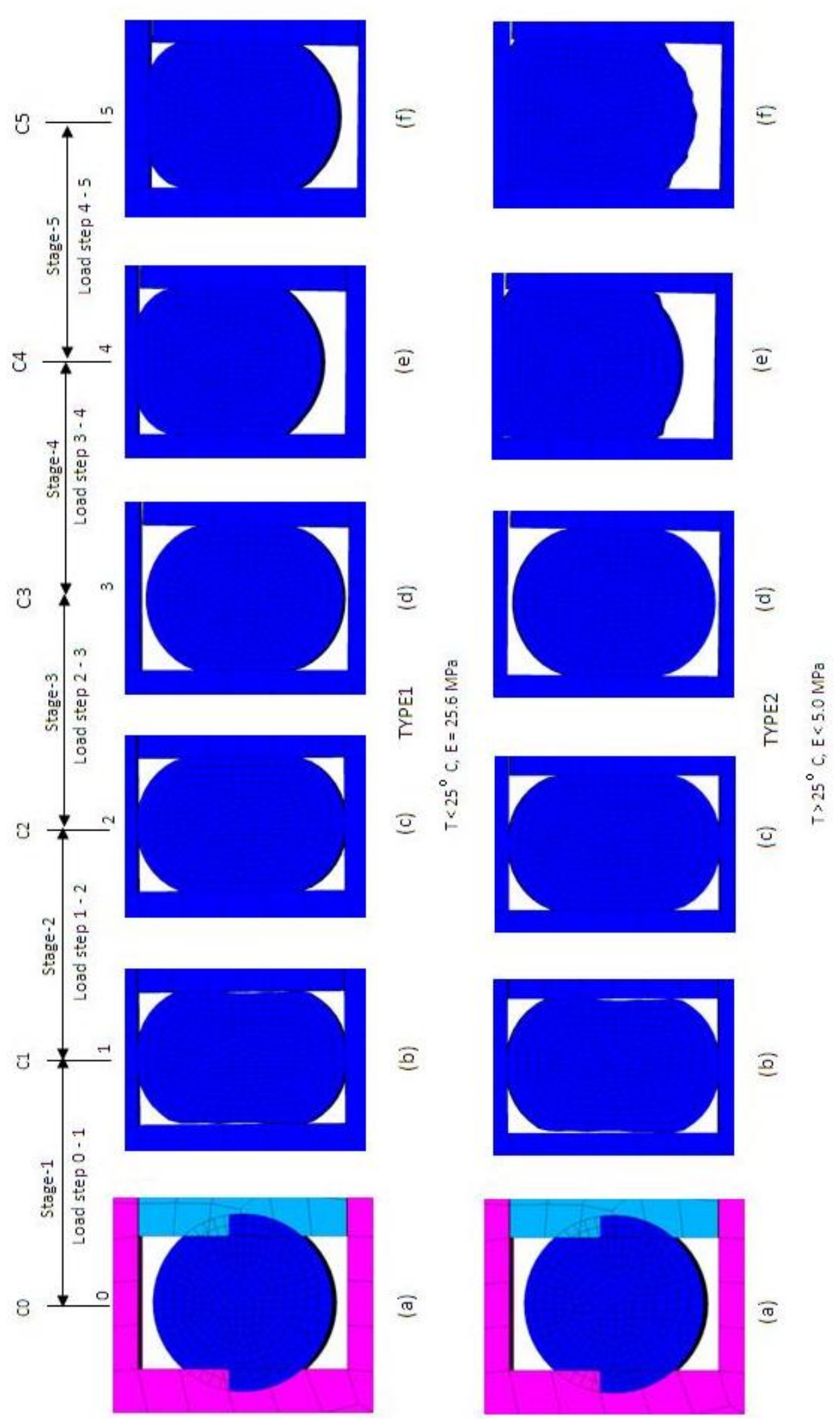

Figure 5. Shape of O-Ring at different stages (a) initial configuration, (b) prescribed displacement at longer face nodes, (c) actual configuration before load application, (d) after design load application, (e) after leaked gas pressure applied and (f) gas temperature applied 


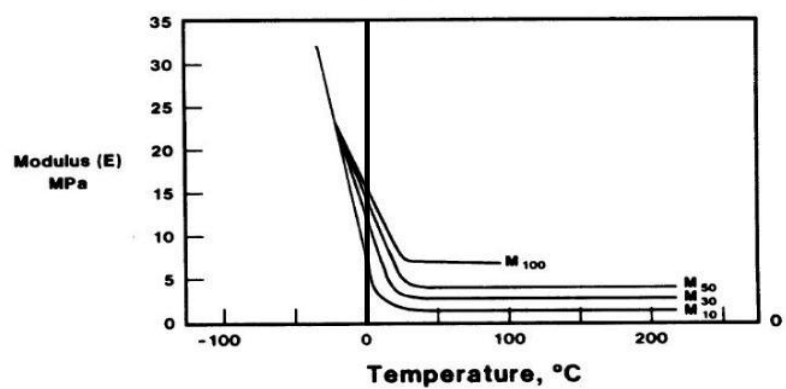

Figure 6. Variation of Young's modulus with temperature for VITON (FKM), O-Ring material (www.sealseastern.com)

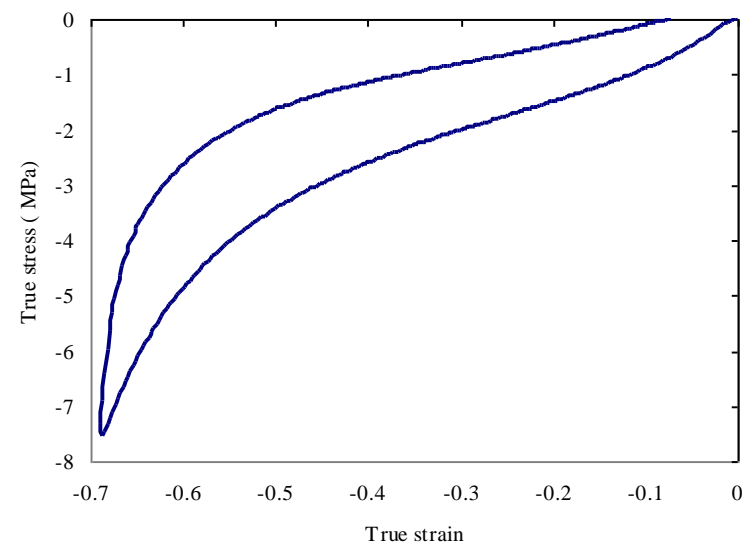

Figure 7. True stress-strain plot for VITON (www.polymerFEM.com)

\section{RESULTS AND DISCUSSIONS}

\subsection{Validation Checks}

The FE modeling of the segment joint used in the stress analysis under the internal pressure value of $6.47 \mathrm{MPa}$ is carried out the validation checks. In this section, three validation checks are carried out and presented to show the numerical accuracy: (i) radial displacements away from the joint, (ii) stresses in the membrane regions away from the joint and (iii) force equilibrium at the pin level. There is no way of validation checks for stresses and strains within the joint region, as analytical / exact solutions are not possible. Convergence check, using four times finer mesh, but using a smaller region, shows about $15 \%$ higher stresses and $12 \%$ higher strains in the linear region. In the plastic region there is no appreciable difference in the stresses, as the level reaches the ultimate value in both cases. Regions away from the joint, beyond the weld line are experiencing the membrane conditions.

\subsubsection{Radial displacement at membrane region}

The deformed configuration of the whole joint with extended region is shown in Figure 8. Regions away from the joint beyond the weld line (about $550 \mathrm{~mm}$ from center of the pin on either side), is seen to be in membrane conditions. The radial displacement from FE model in the membrane region is 10.3 $\mathrm{mm}$, against the value of $10.13 \mathrm{~mm}$ calculated from strength of material approach, by using the formula

$$
\left[\frac{\mathrm{pr}^{2}}{\mathrm{Et}}\left(1-\frac{v}{2}\right)\right]
$$

which shows a difference of $1.7 \%$. Where, $\mathrm{p}=$ internal pressure, $r=$ radius of motor case, $\mathrm{E}=$ Young's modulus of the material, $v=$ Poisson's ratio and $\mathrm{t}=$ thickness of the motor case.

\subsubsection{Stresses at membrane region}

The hoop stress value obtained from FE calculations in the membrane region is $1350 \mathrm{MPa}$. The strength of material formula $\left[\frac{\mathrm{pr}}{\mathrm{t}}\right]$ gives $1342 \mathrm{MPa}$, the difference being $0.6 \%$.

\subsubsection{Force balance in load transfer at pin level}

The axial component of force due to the internal pressure is transferred from one segment to other through the pins. At the pin level, this transfer takes place at two sections / interfaces, one is at the level of interface between clevis outer flange and tang (section B-C interface, Figure 9) and the other is at the level of interface between clevis inner flanges and tang (section D-E, Figure 9) in the form of transverse shear stresses. The variations of the same along the two diametrical planes oriented in the axial direction are shown in Figure 10. The area under the curves are obtained and multiplied by the area of cross section of the pin. The force transmitted through the B-C interface comes to $133863 \mathrm{~N}$ and that through the DE interface comes to $158289 \mathrm{~N}$. The sum of the two is 292152 N. In the FE modeling the axial force applied at the end of each segment. The equivalent comes to $287600 \mathrm{~N}$. The comparison of the two shows a difference of $1.6 \%$. It is observed that the forces transmitted at the two levels are not equal; larger at the D-E interface. This difference happens even though the pin penetration depth on either side of tang is equal. The cause for this unequal load transfer is due to the rotation of the joint.

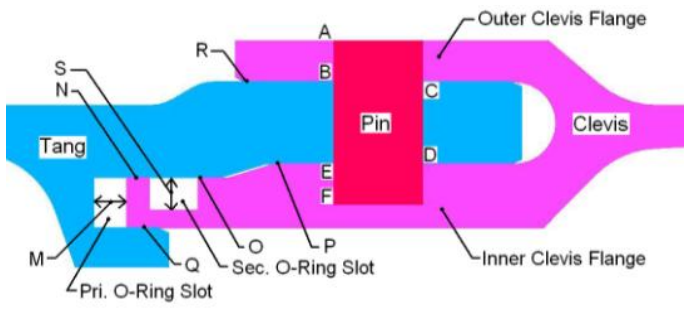

Figure 9. Gap monitoring locations

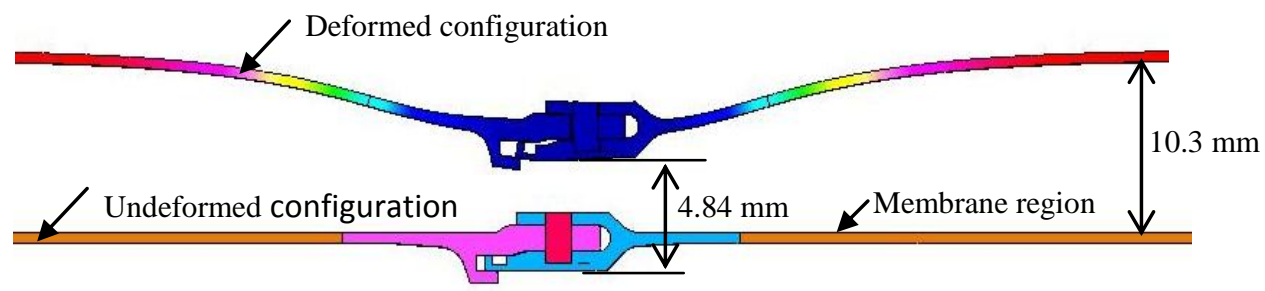




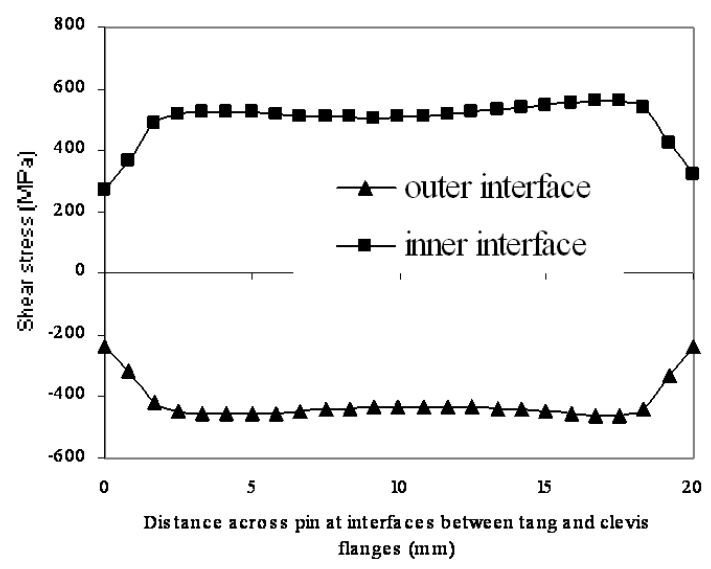

Figure 10. Transverse Shear stress variation across pin

\subsection{Deformation and Gap Formation}

The casing is subjected to internal pressure (design load) of 6.47 $\mathrm{MPa}$, which is the primary load considered in the design of SRBs. The deformed configuration of the whole joint with extended region is shown in Figure 8. It is observed that the radial deformation in the extended (membrane) region is 10.3 $\mathrm{mm}$ and in central region of joint (at pin) it is $4.84 \mathrm{~mm}$. Table 1 shows the gap at the selected locations (refer Figure 9) for the segment joint. The maximum axial relative displacement at primary O-Ring slot $(\mathrm{M})$ is $0.61 \mathrm{~mm}$. At the secondary ORing location (S) the radial relative displacement is $0.23 \mathrm{~mm}$. The gap openings at $\mathrm{M}$ and $\mathrm{S}$ might affected the contact between the O-Ring and slot walls, resulting in leakage of gases It is observed that the presence of capture feature reduce considerably the deformations and hence the gap formation.

Table 1 Gap formation at critical locations

\begin{tabular}{|c|c|c|}
\hline $\begin{array}{c}\text { Gap monitoring } \\
\text { locations }\end{array}$ & Initial gap (mm) & $\begin{array}{c}\text { Gap at full load } \\
(\mathbf{m m})\end{array}$ \\
\hline $\mathrm{M}$ & 7.1 & 7.71 \\
\hline $\mathrm{N}$ & 0.05 & 0.16 \\
\hline $\mathrm{O}$ & 0.05 & 0.26 \\
\hline $\mathrm{P}$ & 0 & 0.15 \\
\hline $\mathrm{Q}$ & 0.05 & 0.011 \\
\hline $\mathrm{R}$ & 0 & 7.38 \\
\hline $\mathrm{S}$ & 7.15 & \\
\hline
\end{tabular}

WWw.ijsea.com

\subsection{Contact Pressure Under Design and Leak Pressure Loads}

The variation of the CPs with loading under the two stages, load step 2-3 and load step 3-4 are shown in Figs. 11 and 12 respectively for primary and secondary O-Rings. Load steps 0-1 and 1-2 are primarily analyses for keeping the O-Rings in the compressed initial stations on the slots. The load step 2-3 refers to the application of design load on the casing (with no load directly on the O-Ring) and load step 3-4 refers to application of leaked gas pressure at the bottom of the primary O-Ring (Figure $3 b$ ) in addition to the design load applied on the casing. The leaked gas is not applied in the secondary ORing. It is seen that the CPs are decreasing with load during load step 2-3, with substantial reduction in primary O-Ring

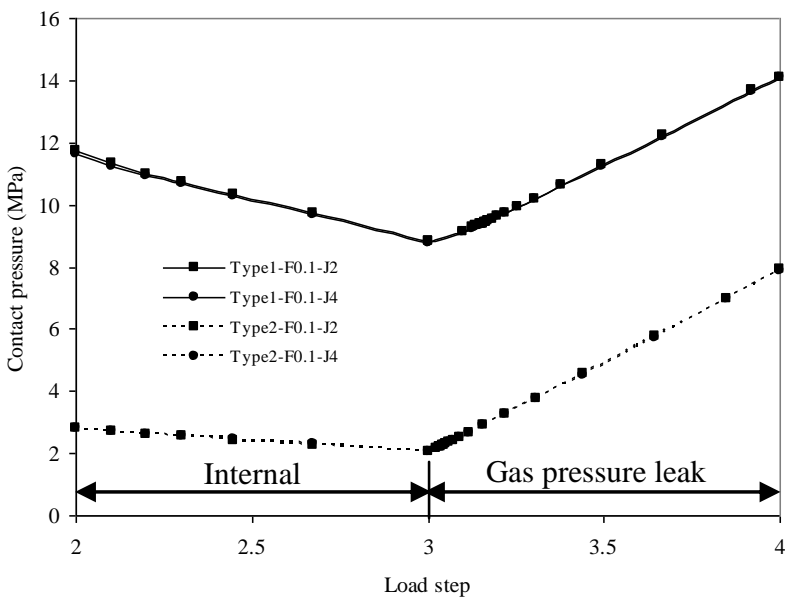

Figure 11. Contact pressure variation at specified points (J2 and J4, refer Fig.3b) on primary O- Ring with $\mu=0.1$

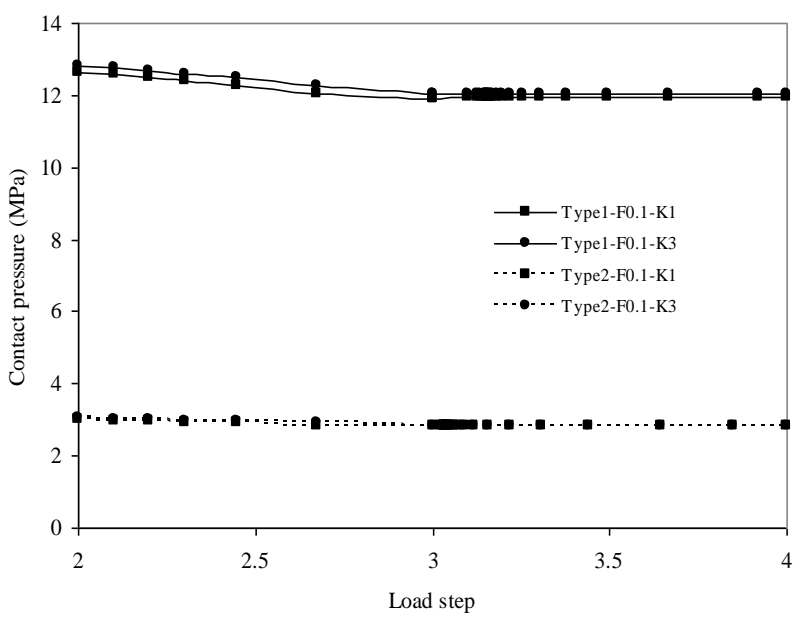

Figure 12. Contact pressure variation at specified points (K1 and K3) on secondary O- Ring with $\mu=0.1$

and marginal reduction in secondary O-Ring. The initial $\mathrm{CP}$ at load step 2 corresponds to the $\mathrm{CP}$ in the as-assembled condition of the motor. In the case of Type 1 material the CPs are $11.72 \mathrm{MPa}$ at $\mathrm{J} 2$ and $11.64 \mathrm{MPa}$ at $\mathrm{J} 4$, similarly for Type 2 material corresponding values are equal at $\mathrm{J} 2$ and $\mathrm{J} 4,2.81$ MPa. The initial contact pressures at load step 2 in the 
secondary O-Ring are marginally higher. The reason for this slight increase in secondary O-Ring is due to the difference in the slot dimensions. During the load step 3-4, there is a substantial increase in the CP for both the material types at primary O-Ring. At $\mathrm{J} 2$, the $\mathrm{CP}$ values increases from 8.83 to 14.1 MPa for Type1 and 2.07 to 7.92 MPa for Type2. In the case of secondary O-Ring, marginal changes are taking place during the load step 3-4, for the simple reason that the leaked gas is not applied on the secondary O-Ring. The corresponding numerical values of CPs are given in Tables 2 and 3 for different frictional coefficients, $\mu=0.1$ and 0.4 . As seen from the tables the frictional coefficient has marginal influence on the CPs. At the end of load step 4, the CP values at $\mathrm{J} 2$ in the primary O-Ring for Type 1 and Type 2 material are 14.1 and 7.92 MPa respectively. More or less the same CPs are observed at J4. J2 and J4 are considered as critical locations from the point of view of arresting the leaked gas moving further in to secondary O-Ring and eventually outside. It is observed that the $\mathrm{CP}$ for Type 1 material is considerably higher than the leaking gas pressure (6.47 MPa). However, for Type 2 material the $\mathrm{CP}$ is marginally greater. As described above, Type1 and Type 2 are the same material (VITON) but at two ambient temperatures, at cold weather condition it is referred as Type1 (temperature $<-25^{\circ} \mathrm{C}$ ) and at hot weather it is Type 2 (temperature $>25^{\circ} \mathrm{C}$ ). Even though the CP is high in the case of Type 1 material and hence it appears to be efficient in arresting leakage of gases beyond primary O-Ring, but in reality it is not. This is because, the VITON material becomes brittle at low temperatures and hence loses the resiliency, the property which determines the rate of recovery and regaining the original shape on removal of externally applied load. This is the one of the reasons attributed to the failure of Space Shuttle Challenger (Anon, 1986)

Table 2 Variation of CPs at specified locations for Type1 O-Ring material (for two frictional values) with load

\begin{tabular}{|c|r|r|r|r|r|r|}
\hline \multirow{2}{*}{ Location No. } & \multicolumn{5}{|c|}{ Contact pressure (MPa) for TYPE1 } \\
\cline { 2 - 7 } & \multicolumn{3}{|c|}{ Friction = 0.1 } & \multicolumn{3}{c|}{ Friction = 0.4 } \\
\cline { 2 - 7 } & $\begin{array}{c}\text { stage 2 } \\
\text { (Initial CP) }\end{array}$ & stage 3 & stage 4 & $\begin{array}{c}\text { stage 2 } \\
\text { (Initial CP) }\end{array}$ & stage 3 & stage 4 \\
\hline Primary O-Ring & & & & & & \\
J1 & 0.62 & 0.00 & 10.19 & 0.64 & 0.00 & 5.63 \\
J2 & 11.72 & 8.83 & 14.10 & 11.75 & 8.85 & 13.26 \\
J3 & 1.60 & 0.00 & 0.00 & 1.62 & 0.00 & 0.00 \\
J4 & 11.64 & 8.80 & 14.10 & 11.67 & 8.79 & 12.54 \\
\hline Secondary O-Ring & & & & & & \\
K1 & 12.63 & 11.92 & 11.95 & 12.60 & 11.84 & 11.87 \\
K2 & 3.74 & 5.09 & 5.19 & 3.81 & 5.49 & 5.64 \\
K3 & 12.82 & 12.04 & 12.04 & 12.79 & 11.91 & 11.92 \\
K4 & 3.49 & 0.00 & 0.00 & 3.51 & 0.00 & 0.00 \\
\hline
\end{tabular}

Table 3. Variation of CPs at specified locations for Type2 O-Ring material (for two frictional values) with load

\begin{tabular}{|c|c|c|c|c|c|c|}
\hline \multirow{2}{*}{ Location No. } & \multicolumn{5}{|c|}{ Contact Pressure (MPa) in TYPE2 } \\
\cline { 2 - 7 } & \multicolumn{3}{|c|}{ Friction = 0.1 } & \multicolumn{3}{c|}{ Friction = 0.4 } \\
\cline { 2 - 7 } & $\begin{array}{c}\text { stage 2 } \\
\text { Initial CP) }\end{array}$ & stage 3 & stage 4 & $\begin{array}{c}\text { stage 2 } \\
\text { (Initial CP) }\end{array}$ & stage 3 & stage 4 \\
\hline Primary O-Ring & & & & & & \\
J1 & 0.27 & 0.00 & 7.14 & 0.31 & 0.00 & 6.05 \\
J2 & 2.81 & 2.07 & 7.92 & 2.83 & 2.06 & 7.68 \\
J3 & 0.45 & 0.00 & 0.00 & 0.49 & 0.00 & 0.00 \\
J4 & 2.82 & 2.07 & 7.90 & 2.84 & 2.07 & 7.32 \\
\hline Secondary O-Ring & & & & & & \\
K1 & 3.00 & 2.82 & 2.82 & 3.00 & 2.80 & 2.80 \\
K2 & 0.89 & 1.21 & 1.23 & 0.92 & 1.33 & 1.36 \\
K3 & 3.05 & 2.84 & 2.84 & 3.05 & 2.81 & 2.81 \\
K4 & 0.90 & 0.00 & 0.00 & 0.92 & 0.00 & 0.00 \\
\hline
\end{tabular}

wWw.ijsea.com

\subsection{Contact Pressures Due To Thermal Load}

Now we consider the thermal effect of the leaking gas. As it passes through the leak path (Figures $3 b$ and 4), it loses heat to a certain extent. In the combustion chamber the temperature is said to be about $3600 \mathrm{~K}$ (Wienholts, et. al, [18]). For the analysis purpose, it is assumed that the gas acting at bottom of the primary O-Ring (Figure $3 b$ ) is at reduced temperature (Perry et al. [13, 14]). The change in CPs due to this leaked gas pressure has been presented in the previous section. In this section the results are presented for the variations of CPs due to the application of thermal loads. The analysis of load step 4-5 is carried out in two levels: (1) thermal analysis and (2) structural analysis. The thermal analysis is carried out for three values of surface temperatures; $\mathrm{T}_{\mathrm{s}}=423\left(150^{\circ} \mathrm{C}\right)$, $573(300)$ and $673 \mathrm{~K}(400)$ as indicated in Figure 3b. The values of $\mathrm{T}_{\mathrm{s}}$ equal to 573 and $673 \mathrm{~K}$ are higher than the operational range of material VITON (Anon, 2001). However, these values are used in the present analysis, they are lower than the ablation temperature, $702 \mathrm{~K}\left(430^{\circ} \mathrm{C}\right)$ (Perry et. al, $[13,14])$ of the material (VITON). Thermal analysis is treated as a linear transient problem (properties independent of temperatures). Heat transfer from the O-Ring to metal and vice-versa is considered by specifying a convective heat transfer coefficient, $\mathrm{h}=0.01 \mathrm{~W} / \mathrm{mm}^{2} \mathrm{~K}$. Heat loss to the atmosphere is accounted for, through convective heat transfer coefficient, $\mathrm{h}=25.0 \mathrm{E}-06 \mathrm{~W} / \mathrm{mm}^{2} \mathrm{~K}$ (Incropera et al., [6] and [8]) by assuming a free convection. The ambient temperature is taken as $303 \mathrm{~K}\left(30^{\circ} \mathrm{C}\right)$. This analysis gives the thermal field both in the O-Ring and surrounding casing material. It is observed that the temperature field reaches the steady state condition at about $60 \mathrm{~s}$. Figure 13 shows the temperature field for $\mathrm{T}_{\mathrm{s}}=423 \mathrm{~K}$. The temperature is decreasing inside the $\mathrm{O}$ Ring and the casing. Similar thermal field in the O-Ring and Casing are obtained for other two specified temperature levels (573 and $673 \mathrm{~K})$.

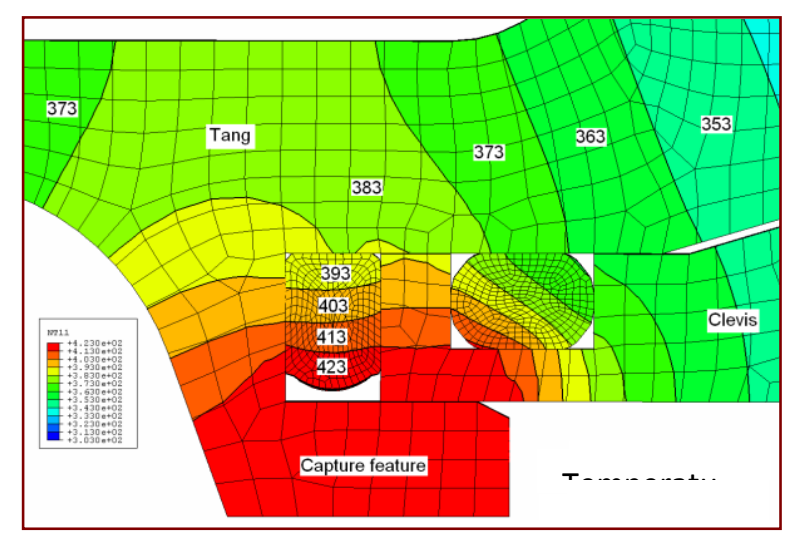

Figure 13. Temperature contours at O-Ring locations for modified joint, Case-2, with $423 \mathrm{~K}$ specified temperature.

At the second level, the CPs are obtained through the structural analysis of the joint by applying the thermal load obtained in first level. This is carried out in the load step 4-5 (stage 5). The coefficient of thermal expansion, $\alpha$ plays a vital role on the CPs. Presently used values are; for O-Rings, 
$\alpha=90.0 \mathrm{E}-06$ in./in. $/{ }^{\circ} \mathrm{F}(162.0 \mathrm{E}-06 \mathrm{~mm} / \mathrm{mm} / \mathrm{K})$ and for casing, $\alpha=12.3 \mathrm{E}-06 \mathrm{~mm} / \mathrm{mm} / \mathrm{K}$. The variation of $\mathrm{CPs}$ with load on primary and secondary O-Rings for the case of Type2 is shown in Figures 14 and 15 for the case of $\mu=0.1$. The CPs are increasing with load. The rate of increase depends on the temperature of the leaking gas. From Figure 14, it is seen that the maximum $\mathrm{CP}$ experienced in the primary O-Ring at $\mathrm{J} 2$ (Figure $3 \mathrm{~b}$ ) is $8.9 \mathrm{MPa}$ for $\mathrm{T}_{\mathrm{s}}=673 \mathrm{~K}$ and $8.2 \mathrm{MPa}$ for $\mathrm{T}_{\mathrm{s}}=$ $423 \mathrm{~K}$. Figure 15 shows the variations of the $\mathrm{CP}$ in secondary O-Ring with load for Type 2 case $(\mu=0.1)$. The CPs are increasing with load, which is caused by the raise in temperature as seen from Figure 13. Figure 16 shows the overall variations of $\mathrm{CP}$ in the primary O-Ring during the load steps 2-3, 3-4 and 4-5 for Type 2 for $\mathrm{T}_{\mathrm{s}}=423 \mathrm{~K}$. This graph is obtained by combining Figs. 11 and 14. It may be seen that the $\mathrm{CP}$ at $\mathrm{J} 2$ decreases from 2.81 to $2.07 \mathrm{MPa}$ at the end of load step 3 (application of design load within the motor, normal function). If leaking of combustion gas through the

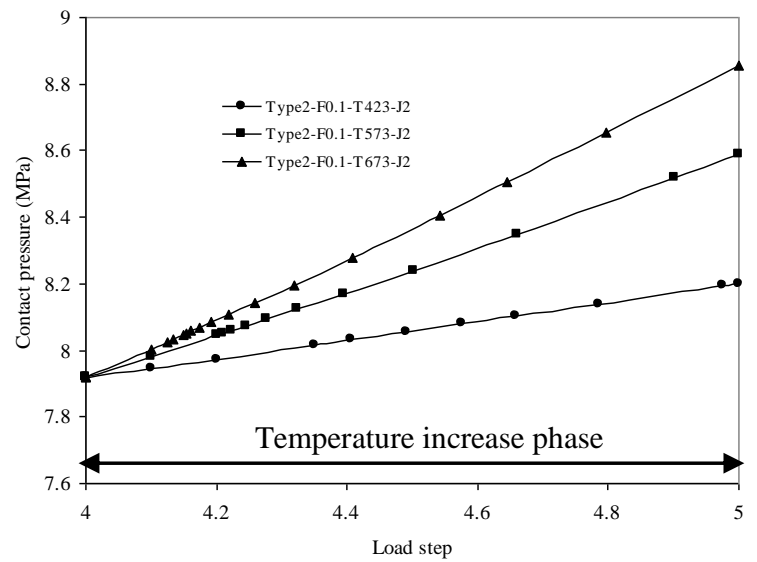

Figure 14 Contact pressure variation at J2 (refer, fig. 3) on the primary O-Ring for different temperature values, $\mu=0.1$, Type 2 O-ring material, Case- 2

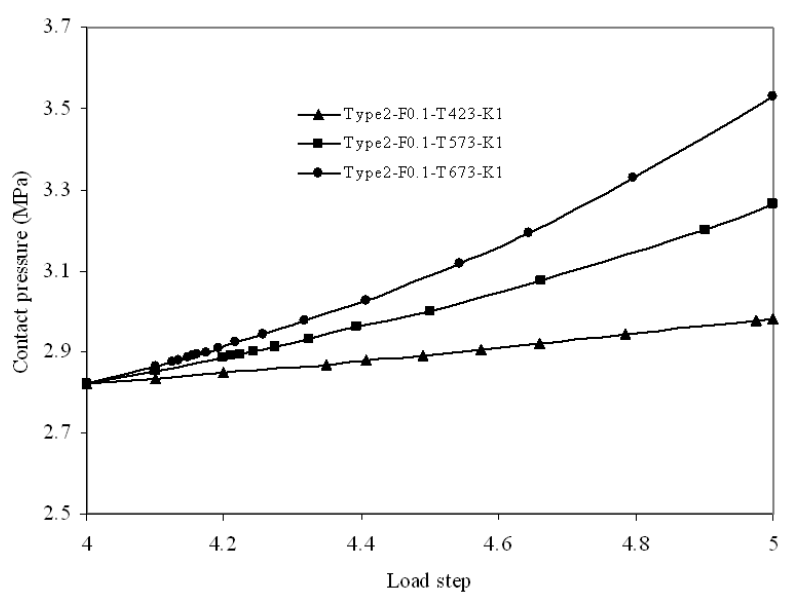

Figure 15 Contact pressure variation at K1 (refer, fig. 3) on the secondary O-Ring for different temperature values, $\mu=0.1$, Type 2 O-ring material, Case- 2 insulation parts of the joint takes place, the $\mathrm{CP}$ increases from 2.07 to $7.92 \mathrm{MPa}$ at the end of load step 4. It increases further to $8.2 \mathrm{MPa}$ due to temperature rise. Because of the low value, $\mathrm{CP}(=2.07 \mathrm{MPa})$ at the end of load step 3 , a question arises, whether the primary O-Ring will be in a position to arrest the leaked gas reaching to the secondary O-Ring. The instant of entry of leaked gas into the primary O-Ring chamber is consider as the critical moment. As soon it enters, the O-Ring is pushed up which in turn causes CPs at $\mathrm{J} 2$ and $\mathrm{J} 4$ to increase sufficiently high. This is expected to prevent the leaking gas reaching the secondary O-Ring.

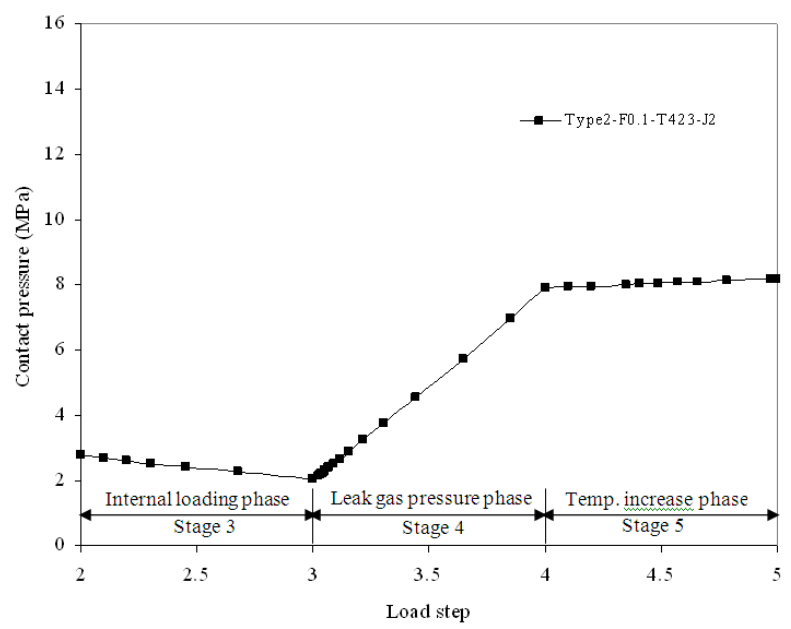

Figure 16. Contact pressure variation at $\mathrm{J} 2$ on primary $\mathrm{O}$ Ring with Type 2 material of O-Ring, Case- 2 with temperature $=423 \mathrm{~K}, \mu=0.1$

\section{CONCLUSION}

The contact pressure between the O-Rings and the slot walls in the joint depends very much on the material property, namely Young's modulus, which in turn depends on the temperature, higher the temperature lower the modulus and vice versa. The initial $\mathrm{CP}$ induced during assembly of segments is higher for lower ambient temperatures and lower for higher temperatures. For tropical weather condition the initial CP is lower than the combustion pressure (design load). When the motor is subjected to this load, the CP decreases further, reaches the value nearly $1 / 3$ of the combustion gas pressure. If leaking occurs and the gas pressure acts directly on the O-Ring, the $\mathrm{CP}$ increases to a value nearly equal to the combustion pressure (pressure sealing effect).Due to the viscoelastic nature of the O-Ring material, there is some time lag in development of contact pressure. In the present work, the O-Ring is treated as an elastic material and hence the contact pressure development at O-Ring level mentioned above is instantaneous. The elastomeric material is having low thermal stability. The structural performance of the same under the hot leaking gas has not been accounted for the present study. These limitations may be focused on the further studies. 


\section{REFERENCES}

[1] ABAQUS, 2004, ABAQUS/Standard User's Manual, Version 6.4, Hibbitt, Karlsson \& Sorensen, Inc,1080, Main street, Pawtucket, R.I, USA.

[2] Anon., 1986, Report of the Presidential Commission on the Space Shuttle Challenger Accident, Washington, DC, June 6.

[3] Anon., 2001, Parker O-Ring Hand Book - Catalog ORD 5700 A/US, Parker Hannifin Corporation, Cleveland, $\mathrm{OH}$.

[4] Bathe, K.J. Finite Element Procedures, Prentice Hall of India, New Delhi. 1996.

[5] Bathe, K.J. and Milos Kojic Inelastic Analysis of Solids and Structures, Springer- Verlag, Berlin, 2005.

[6] Incropera, F.P and DeWitt, D.P, Fundamentals of Heat and Mass Transfer, John Wiley \&Sons, New York, Fifth Edition, 2002.

[7] Kenneth Parsons, Jr. R. 1989, Space shuttle redesigned solid rocket motor joint seal verification, Proceedings of AIAA/ASME/SAE/ASEE $25^{\text {th }}$ Joint Propulsion Conference, Monterey, CA, July, AIAA Paper No. AIAA-1989-2776.

[8] Kothandaraman, C.P. and S. Subramanyan Heat and Mass Transfer Data Book, Fourth Edition, New Age International (P) Limited Publishers, New Delhi, 1996.

[9] Lach, C.L. 1992, Effect of temperature and gap opening rate on the resiliency of candidate solid rocket booster O-ring materials, NASA Technical Paper - 3226, June.

[10] Lach, C.L. 1993, Effect of temperature and O-ring gland finish on sealing ability of Viton V747-75, NASA Technical Paper - 3391, November.

[11] Mark Salita, 1988, Simple finite-element model of O-ring deformation and activation during squeeze and pressurization, Journal of Propulsion and Power, 4, 497-511.

[12] Palaninathan, R. 2005, S200 motor case structural analysis for handling and testing conditions, Department of Applied Mechanics, Indian Institute of Technology, Madras, Project report submitted to Vikram Sarabhai Space Centre (VSSC), ISRO.

[13] Perry, M. and N. Eddy, 1989, Design and thermal verification of the space shuttle redesigned solid rocket motor field joint. Proceedings of AIAA/ASME/ SAE/ASEE 25 $5^{\text {th }}$ Joint Propulsion Conference, Monterey, California, July, AIAA Paper No. AIAA-989-2775.

[14] Perry, M., N. Eddy, L. Gruet and J. Maw, 1991, Space shuttle redesigned solid rocket motor field joint verification, Journal of Propulsion and Power, 7, 130-145.

[15] Ruddell, D. and R. Buttars, 1989, Space shuttle SRM igniter and field joint thermal analyses, Proceedings of AIAA/ASME/SAE/ASEE $25^{\text {th }}$ Joint Propulsion Conference, Monterey, California, July, AIAA Paper No. AIAA-1989-2874.

[16] Sivakumar, V. 2006, A nonlinear analysis of segment joint in solid rocket boosters, Ph.D. thesis, Indian Institute of Technology, Madras.

[17] Stein, S.R. 1989, Seal material selection, design and performance- advancements from the space shuttle booster redesign, Proceedings of AIAA/ ASME /SAE IASEE 25 $5^{\text {th }}$ Joint Propulsion Conference,
Monterey, California, July, AIAA Paper No. AIAA1989-2774.

[18] Wienholts, E.J. and P.M. Nguyen, 1989, 3-D Flow/thermal analysis of a defect in the RSRM field joint. Proceedings of AIAA/ASME/SAE/ASEE $25^{\text {th }}$ Joint Propulsion Conference, Monterey, California, July, AIAA Paper No. AIAA- 1989-2778. 